\title{
Exploring Contemporaneous Correlations Among BRICS Stock Markets
}

\author{
Shalini TALWAR ${ }^{\star}$
}

\begin{abstract}
A B S T R A C T
In the current paper, the author has used daily closing price data of the selected equity indices of the five BRICS countries from a period of 2010 to 2017 to understand the extent of co-movement among them and to evaluate the existence of portfolio diversification opportunities they present together. Econometric tools have been used to diagnose unidirectional and/or bidirectional causality, long-run co-movement and short-run contemporaneous correlations among these markets. The findings reveal potentially profitable investment prospects. Vigour of the results has been tested in two ways. First, Granger causality and VAR estimates have been retested for a different time horizon using daily data from 2000 to 2007 . The second robustness check has been done by evaluating the outcome of VAR by changing the Cholesky ordering for the data from 2010 to 2017.
\end{abstract}

(C) 2019 EAI. All rights reserved.

\section{Introduction}

For a long time, the domestic financial markets had moved to domestic cues and were modelled on separate univariate models for predicting various issues of financial econometrics. However, the markets are no longer operating in isolation and have become more integrated and globalized. Financial markets across the globe are highly intricate with complex interconnectedness. Though the globalisation of financial markets is a good harbinger of increased portfolio diversification opportunities but the evidence of negative spill over, domino effect in transmission of fluctuations and erratic returns have made international investors cautious and sceptical. International diversification opportunities have definitely come with a cost attached to them. The recent evidence of financial volatilities moving together and the correlations increasing with higher instability is quite extensive. Research shows evidence that the global capital markets move in tandem. The effect of fluctuations in one market has contagion effect on the other markets. This becomes visually clearer during the time of a crisis.

The crisis of 2008, which started in US as sub-prime lending crisis in the housing segment and spread like wildfire across the world, gave a clear demonstration of how a black swan event in the US market caused a meltdown around the world. There was evidence of stock exchanges falling by about $10 \%$ in Tokyo and $5 \%$ in Europe. Many exchanges had suspended the trade in view of continued decline in stock exchange due to the crisis. Some of the other examples include interest rate increase in US causing the NIFTY and BSESENSEX to go haywire; the stock market crash of 2015 in China spooked the Indian Indices to plunge about 450 points. Markets adjust to global feeds. This interesting fact of interconnectedness has given rise to much of the study lately in the financial world. An understanding of linkages among markets is required to enhance the knowledge of the direction of risk transmission across markets and identification of markets that are, in a way, leading indicators of fluctuations in others.

The current study is undertaken with intention to find static correlations between 5 BRICS countries, namely, Brazil, Russia, India, China and South Africa. Daily closing price level of the indices representing the BRICS equity markets, namely, BOVESPA, BSESENSEX, MICEX, SCI and SAF40, over a period from 2010 to 2017 is used for the study. The results indicate that BVSP is the most influential index among the 5 indices and South Africa has negligible contemporaneous correlation with other BRICS markets.

\section{Literature review}

Much of research conducted in equity markets is based on finding the causal relationship of market with macroeconomic indicators. Zeren et al. (2016) examined the market indices of Turkey, Japan and England to diagnose their relationship with exchange rate movements. They used time varying causality test with bootstrap developed by R. Scott Hacker and Abdul Nasser Hatemi-J as they believed that causality will be 
different in different periods due to political and economic crisis. It was found that that the three countries had two-way causality in the period from January 1990 and April 2013 when different crisis were unfolding at both, the local and global level.

Plihal (2016) studied the relationship between different macroeconomic parameters like unemployment rate, interest rate, rate of inflation etc. and market indices in Germany countries. Further, research done based on such econometric test was conducted by Alexandr Cerny (2004), who examined how fast information transmitted in one market showed effect in another market using market indices of US, London, Frankfurt, Paris, Warsaw and Prague. The tests analyzing 8 months' data with frequencies ranging from 5 mins to 1 day for the market indices revealed that these markets reacted very fast, some as fast as 30 minutes.

Chandran and Rao (2009) examined the relationship between stock market of Malaysia and the emerging East Asian countries, namely South Korea, Taiwan, Hong Kong and Japan and found long-run cointegration between markets of Malaysia and South Korea. Folfas (2016) studied causal relationship between markets of the three countries in the North American continent. Bivariate Granger causality was detected for American and Canadian markets in two periods, namely, 1980-1988 and 1994-2013. Furthermore, while American market was found to Granger-caused Mexican one, the Canadian market did not Granger-cause it at all. Vyrost and Baumöhl (2010) performed Granger causality analysis on stock market indices from several Asian, European, and U.S. markets. They studied the potential problems caused by nonsynchronicity, including the one induced by differing numbers of observations being analysed and the different time zones in which the markets operate. They proposed data matching technique and modified granger causality test to account of both the non-synchronous effects. Most of the proposed associations were not found to be significant. However, the application of adjusted methodology rejected the proposed Granger non-causal relationship in all cases.

\section{Methods and Data \\ 3.1 Methods}

The study aims to investigate the extent of co-movement between the equity markets of BRICS countries. For this purpose, daily price levels of the selected indices have been first tested for unit root using the Augmented Dickey-Fuller (ADF) test $(1979,1981)$. Existence of unit root may lead to spurious regression as emphasized by Granger and Newbold (1974), so the series need to be made stationary before any tests are applied to evaluate the contemporaneous correlations between them. Once all series has been made stationary by taking first difference, Granger causality test (Granger 1969,1988) has been utilized to explore causality between the pairs of indices and determine the influential market among them.

Thereafter, Johansen cointegration (Johansen, 1991) test is applied to test long-run co-movement between the series under the study. Confirmation of cointegration indicates long-run equilibrium relationship. Existence of cointegration is interpreted through two tests, namely, the trace test and the maximum eigenvalue test.

If there are no cointegrating equations between the pairs of variables under the study, short-run relationship among them is tested using vector autoregression (Sims, 1980). The VAR ordering used herein is not Cholesky time zone, rather it is in the order of the acronym. The lag length to be used is determined using the classical lag length criteria, namely, Akaike Information Criteria (AIC) (Akaike, 1974), Schwarz Information Criteria (SIC) (Schwarz, 1978) or Hannan-Quinn Information Criteria (HQ) (Hannan-Quinn, 1979). The results of VAR estimation are interpreted based on Block Exogeneity Wald Test and variance decomposition test.

\subsection{Data}

We have used daily closing price level of BVSP, MICEX, SENSEX, SCI and SAF40 drawn from WSJ historic record and Yahoo Finance to analyse static correlations among BRICS countries for a period from 2010 to 2017. The series utilized are described in table 1.

\section{Table 1. Description of series}

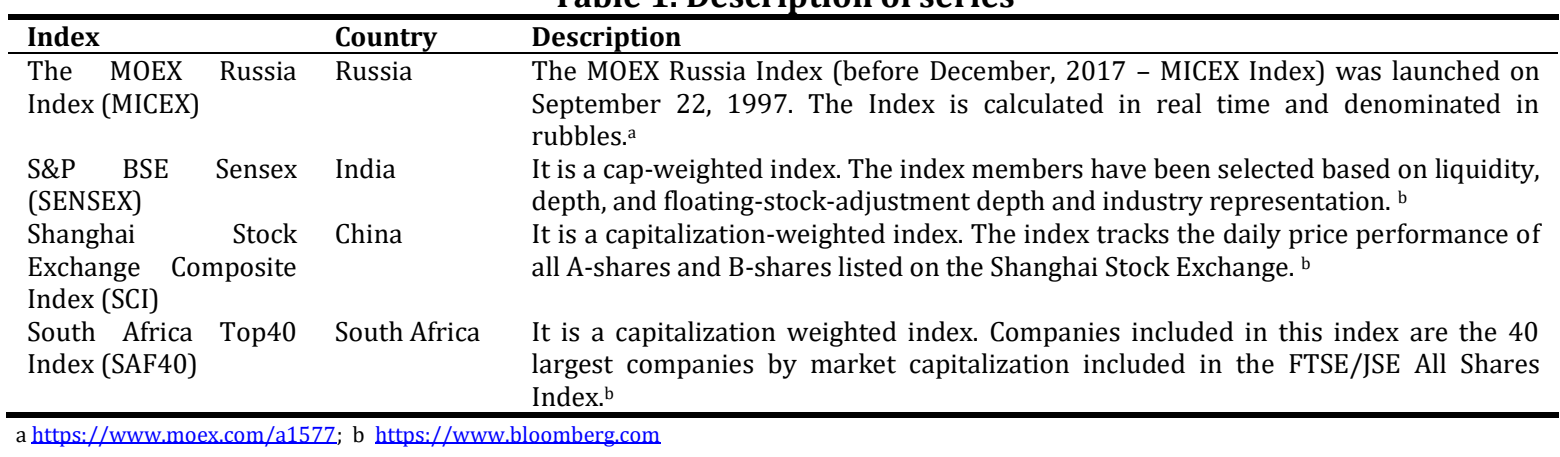


Summary statistics of the daily returns data of all the indices under the study are given in table 2 . The statistics reveal that the daily returns of the Brazilian stock market have averaged around 0.10 per cent during this period. During the same period, the Russian market returned an average of 0.03 per cent daily. The Indian market has fared the best with a daily return of half a per cent on an average. However, it has also been the most volatile market as shown by its standard deviation which is highest amongst the markets under the study. Brazilian market has also been quite volatile. Further, the skewness of more than 0 and kurtosis of more than 3 for all markets confirms that these markets follow leptokurtic distribution with fat tails, implying higher volatility and less clustering of returns around the mean. The Jarque Bera values also confirm non-normal distribution of returns.

Table 2. Descriptive statistics

\begin{tabular}{llllll}
\hline & RETBVSP & RETMICEX & RETSENSEX & RETSCI & RETSAF40 \\
Mean & 0.010 & 0.029 & 0.050 & 0.001 & 0.039 \\
Median & 0.040 & 0.038 & 0.057 & 0.034 & 0.048 \\
Maximum & 8.603 & 6.758 & 5.261 & 10.045 & 4.680 \\
Minimum & -9.211 & -8.400 & -6.120 & -10.629 & -4.070 \\
Std. Dev. & 1.720 & 1.528 & 1.227 & 1.746 & 0.990 \\
Skewness & -0.276 & -0.505 & -0.236 & -0.654 & -0.180 \\
Kurtosis & 5.457 & 6.194 & 5.485 & 8.837 & 4.532 \\
Jarque-Bera & 348.056 & 616.970 & 351.603 & 1966.306 & 136.005 \\
Probability & 0.000 & 0.000 & 0.000 & 0.000 & 0.000 \\
\hline
\end{tabular}

Augment Dickey Fuller test revealed that all series follow I(1) process, that is, they become stationary at first difference (table 3).

Table 3. Results of ADF

\begin{tabular}{lcc}
\hline LEVEL \& INTERCEPT & t-Stat & p-Val \\
\hline BVSP & -1.79 & 0.39 \\
MICEX & -1.31 & 0.62 \\
SENSEX & -0.05 & 0.95 \\
SCI & -1.77 & 0.40 \\
SAF40 & -1.90 & 0.33 \\
FIRST DIFF \& INTERCEPT & t-Stat & P-Val \\
BVSP & $-3.6 \mathrm{E}+01$ & $3.7 \mathrm{E}-22$ \\
MICEX & $-3.6 \mathrm{E}+01$ & $4.9 \mathrm{E}-23$ \\
SENSEX & $-3.5 \mathrm{E}+01$ & $6.5 \mathrm{E}-25$ \\
SCI & $-9.4 \mathrm{E}+00$ & $9.8 \mathrm{E}-17$ \\
SAF40 & $-1.4 \mathrm{E}+01$ & $3.3 \mathrm{E}-29$ \\
\hline
\end{tabular}

\section{Results of Analysis}

The results of all tests are reported in this section. Granger causality output, displayed in table 4, shows that unidirectional causality runs from Brazils' index to Russian, Indian and Chinese indices. Further, unidirectional causality runs from Russian and Indian indices to the Chinese index. There is no causality running from the South African market to other BRICS markets or from other BRICS markets to the South African market.

Table 4. Granger causality test (2010-2017)

\begin{tabular}{lcc}
\hline Null Hypothesis: & F-Statistic & Prob. \\
\hline MIC_2 does not GC BVP_2 & 0.17 & 0.84 \\
BVP_2 does not GC MIC_2 & 11.94 & $7.00 \mathrm{E}-06^{*}$ \\
SEN_2 does not GC BVP_2 & 0.52 & 0.60 \\
BVP_2 does not GC SEN_2 & 28.42 & $8.00 \mathrm{E}-13^{*}$ \\
SCI_2 does not GC BVP_2 & 0.66 & 0.52 \\
BVP_2 does not GC SCI_2 & 11.52 & $1.00 \mathrm{E}-05^{*}$ \\
SAF_2 does not GC BVP_2 & 1.40 & 0.25 \\
BVP_2 does not GC SAF_2 & 1.36 & 0.26 \\
SEN_2 does not GC MIC_2 & 0.39 & 0.68 \\
MIC_2 does not GC SEN_2 & 2.32 & 0.10 \\
SCI_2 does not GC MIC_2 & 0.16 & 0.86 \\
MIC_2 does not GC SCI_2 & 3.16 & $0.04^{*}$ \\
SAF_2 does not GC MIC_2 & 0.01 & 0.99 \\
MIC_2 does not GC SAF_2 & 0.13 & 0.87 \\
SCI_2 does not GC SEN_2 & 0.86 & 0.42 \\
\hline
\end{tabular}




\begin{tabular}{lcc}
\hline Null Hypothesis: & F-Statistic & Prob. \\
\hline SEN_2 does not GC SCI_2 & 3.03 & $0.05^{*}$ \\
SAF_2 does not GC SEN_2 & 2.50 & 0.08 \\
SEN_2 does not GC SAF_2 & 0.87 & 0.42 \\
SAF_2 does not GC SCI_2 & 1.80 & 0.17 \\
SCI_2 does not GC SAF_2 & 0.83 & 0.43 \\
\hline
\end{tabular}

* Indicates rejection of null at $5 \%$ level of significance

MIC_2= RETMICEX_2, BVP_2 =RETBVSP_2, SEN_2 = RETSENSEX_2, SCI_2 = RETSCI_2,SAF_2 = RETSAF40_2

$\mathrm{GC}=$ Granger cause

A look back at the causality relationship among pairs of BRICS markets during 2000 to 2007 period reveals that unlike the evidence shown the recent data of 2010 to 2017, the Brazilian market did not Granger cause the Chinese market. Further, from 2000 to 2007, the Russian market Granger caused the Indian market, a relationship that had disappeared when analysed using the 2010 to 2017 data. Further, there was no unidirectional causality running from Russian and Indian markets respectively to the Chinese market as seen in table 5 displaying the results of analysis using 2000 to 2007 data. As discussed above, now there is a causality running from both the above two markets to China. Other causalities or their absence thereof have been consistent in outcome for both the periods under the discussion.

Table 5. Granger causality test (2000-2007)

\begin{tabular}{lcc}
\hline Null Hypothesis: & F-Statistic & Prob. \\
\hline MIC_1does not GC BVP_1 & 1.58 & 0.21 \\
BVP_1 does not GC MIC_1 & 27.49 & $2.00 \mathrm{E}-12^{*}$ \\
SEN_1 does not GC BVP_1 & 0.23 & 0.8 \\
BVP_1 does not GC SEN_1 & 25.58 & $1.00 \mathrm{E}-11^{*}$ \\
SCI_1 does not GC BVP_1 & 0.28 & 0.76 \\
BVP_1 does not GC SCI_1 & 2.2 & 0.11 \\
SAF_1 does not GC BVP_1 & 0.37 & 0.69 \\
BVP_1 does not GC SAF_1 & 0.44 & 0.64 \\
SEN_1 does not GC MIC_1 & 1.82 & 0.16 \\
MIC_1does not GC SEN_1 & 4.56 & $0.01 *$ \\
SCI_1 does not GC MIC_1 & 0.38 & 0.69 \\
MIC_1does not GC SCI_1 & 1.19 & 0.3 \\
SAF_1 does not GC MIC_1 & 1.26 & 0.29 \\
MIC_1does not GC SAF_1 & 2.57 & 0.08 \\
SCI_1 does not GC SEN_1 & 0.03 & 0.97 \\
SEN_1 does not GCSCI_1 & 0.83 & 0.44 \\
SAF_1 does not GC SEN_1 & 1.41 & 0.24 \\
SEN_1 does not GC SAF_1 & 1.95 & 0.14 \\
SAF_1 does not GCSCI_1 & 0.47 & 0.63 \\
SCI_1 does not GC SAF_1 & 0.62 & 0.54 \\
\hline
\end{tabular}

* Indicates rejection of null at $5 \%$ level of significance

MIC_1= RETMICEX_1, BVP_1=RETBVSP_1, SEN_1 = RETSENSEX_1, SCI_1 = RETSCI_1, SAF_1= RETSAF40_1

$\mathrm{GC}=$ Granger cause

Next Johansen cointegration test is conducted to further understand the associationship between the pairs of BRICS markets. The results show that there is no cointegrating relationship between any of the pairs of the variables (table 6).

Table 6. Johansen cointegration test

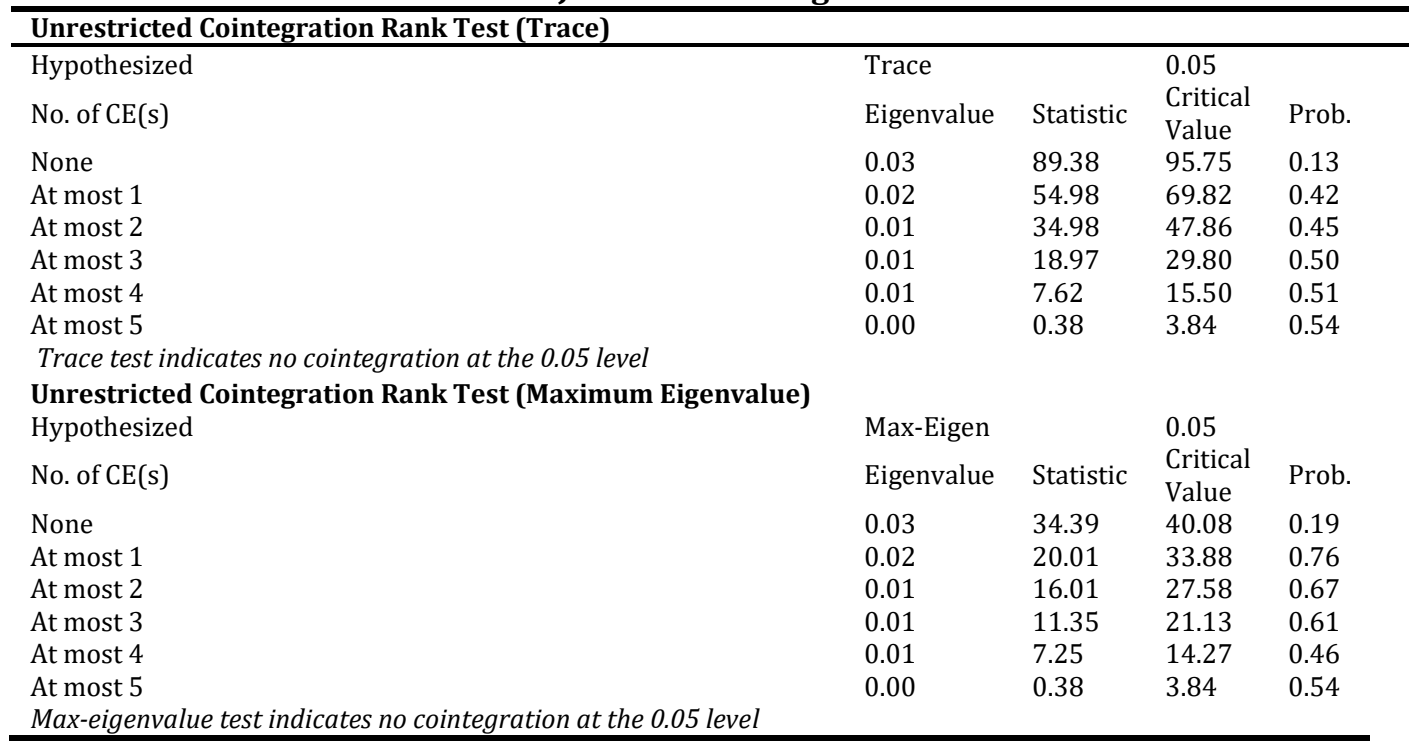


Since no long-run relationship is detected between pairs of indices under the study, VAR is applied to understand their short-term contemporaneous relationship. VAR is calculated at lag length of 1 , as indicated by all three lag length criteria, as given in table 7. Decision is made on basis of majority indication.

Table 7. VAR lag order selection criteria

\begin{tabular}{clll}
\hline Lag & AIC & SC & HQ \\
\hline 0 & -35.6 & $-35.57^{*}$ & -35.6 \\
1 & $-35.66^{*}$ & -35.5 & $-35.59^{*}$ \\
2 & -35.6 & -35.3 & -35.5 \\
3 & -35.6 & -35.2 & -35.4 \\
4 & -35.6 & -35.0 & -35.4 \\
5 & -35.6 & -34.8 & -35.3 \\
6 & -35.5 & -34.7 & -35.2 \\
7 & -35.5 & -34.5 & -35.1 \\
8 & -35.5 & -34.3 & -35.1 \\
\hline \\
cates lag order selected by the criterion \\
Akaike information criterion \\
Chwarz information criterion \\
Hannan-Quinn information criterion
\end{tabular}

The results of VAR are reported in tables 8 and 9.

Table 8. VAR Granger causality/block exogeneity Wald test

\begin{tabular}{lll}
\hline Dependent variable: RETBVSP & & \\
\hline Excluded & Chi- & Prob. \\
RETMICEX & 0.02 & 0.90 \\
RETSENSEX & 0.50 & 0.48 \\
RETSCI & 0.30 & 0.59 \\
RETSAF40 & 2.06 & 0.15 \\
All & 2.74 & 0.60 \\
Dependent variable: RETMICEX & & \\
RETBVSP & 22.64 & $0^{*}$ \\
RETSENSEX & 0.11 & 0.74 \\
RETSCI & 0.00 & 0.97 \\
RETSAF40 & 0.00 & 0.98 \\
All & 22.91 & $0.00^{*}$ \\
Dependent variable: RETSENSEX & & \\
RETBVSP & 52.83 & $0^{*}$ \\
RETMICEX & 0.00 & 0.97 \\
RETSCI & 5.36 & $0.02^{*}$ \\
RETSAF40 & 1.20 & 0.27 \\
All & 61.69 & $0^{*}$ \\
Dependent variable: RETSCI & & \\
RETBVSP & 13.29 & $0.00^{*}$ \\
RETMICEX & 0.23 & 0.64 \\
RETSENSEX & 1.29 & 0.26 \\
RETSAF40 & 1.18 & 0.28 \\
All & 23.44 & $0.00^{*}$ \\
Dependent variable: RETSAF40 & & \\
RETBVSP & 2.49 & 0.12 \\
RETMICEX & 0.03 & 0.86 \\
RETSENSEX & 0.43 & 0.51 \\
RETSCI & 0.00 & 0.98 \\
All & 2.73 & 0.60 \\
\hline cates rejection of the null of no causality at $5 \%$ level of significance
\end{tabular}

The result of Block exogeneity Wald test shows that no causality runs from all other BRICS markets to the Brazilian market. This can be seen from the value of probability above 0.05 , because of which, the hypothesis of no causality cannot be rejected. Causality runs from Brazilian to the Chinese and Indian markets, as well as from all the other markets taken together. Additionally, China is also found to have causality running to India. Further, causality is seen to run from Brazilian market to the Russian markets as well as from all the other markets taken together. There is no causality or transmission of shock from other BRICS markets to South African markets or vice-versa.

Table 9. Variance decomposition estimation (2010-2017)

\begin{tabular}{llllll}
\hline \multicolumn{2}{l}{ Variance Decomposition of RETBVSP: } & & & & \\
\hline Period & RETBVSP & RETMICEX & RETSENSEX & RETSCI & RETSAF40 \\
1 & 100 & 0 & 0 & 0 & 0 \\
2 & 99.80 & 0.01 & 0.03 & 0.02 & 0.16 \\
3 & 99.79 & 0.01 & 0.03 & 0.02 & 0.16 \\
\hline
\end{tabular}




\begin{tabular}{|c|c|c|c|c|c|}
\hline \multicolumn{6}{|c|}{ Variance Decomposition of RETBVSP: } \\
\hline 4 & 99.79 & 0.01 & 0.03 & 0.02 & 0.16 \\
\hline 5 & 99.79 & 0.01 & 0.03 & 0.02 & 0.16 \\
\hline \multicolumn{6}{|c|}{ Variance Decomposition of RETMICEX: } \\
\hline Period & RETBVSP & RETMICEX & RETSENSEX & RETSCI & RETSAF40 \\
\hline 1 & 15.76 & 84.24 & 0.00 & 0.00 & 0.00 \\
\hline 2 & 17.00 & 83.00 & 0.01 & 0.00 & 0.00 \\
\hline 3 & 17.00 & 82.99 & 0.01 & 0.00 & 0.00 \\
\hline 4 & 17.00 & 82.99 & 0.01 & 0.00 & 0.00 \\
\hline 5 & 17.00 & 82.99 & 0.01 & 0.00 & 0.00 \\
\hline \multicolumn{6}{|c|}{ Variance Decomposition of RETSENSEX: } \\
\hline Period & RETBVSP & RETMICEX & RETSENSEX & RETSCI & RETSAF40 \\
\hline 1 & 8.22 & 8.53 & 83.25 & 0.00 & 0.00 \\
\hline 2 & 11.85 & 8.16 & 79.53 & 0.37 & 0.09 \\
\hline 3 & 11.86 & 8.16 & 79.51 & 0.37 & 0.09 \\
\hline 4 & 11.86 & 8.16 & 79.51 & 0.37 & 0.09 \\
\hline 5 & 11.86 & 8.16 & 79.51 & 0.37 & 0.09 \\
\hline \multicolumn{6}{|c|}{ Variance Decomposition of RETSCI: } \\
\hline Period & RETBVSP & RETMICEX & RETSENSEX & RETSCI & RETSAF40 \\
\hline 1 & 3.11 & 1.74 & 1.64 & 93.51 & 0.00 \\
\hline 2 & 4.62 & 1.76 & 1.71 & 91.82 & 0.09 \\
\hline 3 & 4.62 & 1.76 & 1.71 & 91.81 & 0.09 \\
\hline 4 & 4.62 & 1.76 & 1.71 & 91.81 & 0.09 \\
\hline 5 & 4.62 & 1.76 & 1.71 & 91.81 & 0.09 \\
\hline \multicolumn{6}{|c|}{ Variance Decomposition of RETSAF40: } \\
\hline Period & RETBVSP & RETMICEX & RETSENSEX & RETSCI & RETSAF40 \\
\hline 1 & 0.00 & 0.02 & 0.15 & 0.11 & 99.71 \\
\hline 2 & 0.17 & 0.03 & 0.18 & 0.11 & 99.51 \\
\hline 3 & 0.17 & 0.03 & 0.18 & 0.11 & 99.50 \\
\hline 4 & 0.17 & 0.03 & 0.18 & 0.11 & 99.50 \\
\hline 5 & 0.17 & 0.03 & 0.18 & 0.11 & 99.50 \\
\hline
\end{tabular}

Variance decomposition has been estimated for 5 days and consistent with the model definition, contemporaneous variance of BVSP is attributed fully to its own shock. No contemporaneous variance of fluctuation in BVSP on day 1 is expected on account of VAR ordering. Day 2 onwards also, shock to BVSP accounts for more than $99 \%$ of fluctuation in itself and negligible variation comes from the other markets. So the impact of others is quite small. More than $80 \%$ of the variation in MICEX comes from its own innovation on all 5 days and most of the remaining fluctuation comes from BVSP. The variation in SESEX comes largely from itself on the first day except approximately $8 \%$ coming from BVSP and MICEX each. From day 2 onwards, $20 \%$ comes from MICEX and BVSP. The impact of others is negligible on all days. In case of SCI, almost $94 \%$ of its variance comes from its own shock on day 1 with only $6 \%$ coming from BVSP, SENSEX and SCI together. On rest of the days, the impact of others is about $10 \%$. More than $99 \%$ of variance of SAF comes from its own shock on all 5 days.

VAR is also calculated for a different set of data (2000-2007) to provide a perspective on changes in the contemporaneous correlations among the markets under the study. This knowledge can help investors take more informed decisions with regard to holding period. The results of variance decomposition run for all the markets for data from 2000 to 2007 is given in table 10. The impact of Russian market was a little bit more than the recent times on the Brazilian markets from day 2 to day 5. The fluctuations in Russian markets from day one onwards in response to fluctuations in Brazilian markets were less during 2000 to 2007 period. SENSEX accounted for 90 per cent of its own variation in the past but has now become little more sensitive to the variations in Brazil and Russia as indicated by the analysis of 2010 to 2017 data. China is also more susceptible to fluctuations in Brazil, India and Russia now as compared to the period before 2010. South Africa has remained more or less the same, by accounting for more than 99.7 per cent of its own variance during both the periods under the study.

Table 10. Variance decomposition estimation (2000-2007)

\begin{tabular}{|c|c|c|c|c|c|}
\hline \multicolumn{6}{|c|}{ Variance Decomposition of RETBVSP: } \\
\hline Period & RETBVSP & RETMICEX & RETSENSEX & RETSCI & RETSAF40 \\
\hline 1 & 100.00 & 0.00 & 0.00 & 0.00 & 0.00 \\
\hline 2 & 99.76 & 0.19 & 0.01 & 0.03 & 0.01 \\
\hline 3 & 99.76 & 0.19 & 0.01 & 0.03 & 0.01 \\
\hline 4 & 99.76 & 0.19 & 0.01 & 0.03 & 0.01 \\
\hline 5 & 99.76 & 0.19 & 0.01 & 0.03 & 0.01 \\
\hline \multicolumn{6}{|c|}{ Variance Decomposition of RETMICEX: } \\
\hline Period & RETBVSP & RETMICEX & RETSENSEX & RETSCI & RETSAF40 \\
\hline 1 & 12.17 & 87.83 & 0.00 & 0.00 & 0.00 \\
\hline 2 & 15.26 & 83.78 & 0.76 & 0.08 & 0.13 \\
\hline 3 & 15.29 & 83.74 & 0.76 & 0.08 & 0.13 \\
\hline 4 & 15.29 & 83.74 & 0.76 & 0.08 & 0.13 \\
\hline
\end{tabular}




\begin{tabular}{|c|c|c|c|c|c|}
\hline \multicolumn{6}{|c|}{ Variance Decomposition of RETBVSP: } \\
\hline 5 & 15.29 & 83.74 & 0.76 & 0.08 & 0.13 \\
\hline \multicolumn{6}{|c|}{ Variance Decomposition of RETSENSEX: } \\
\hline Period & RETBVSP & RETMICEX & RETSENSEX & RETSCI & RETSAF40 \\
\hline 1 & 6.80 & 3.06 & 90.15 & 0.00 & 0.00 \\
\hline 2 & 10.11 & 2.97 & 86.70 & 0.02 & 0.20 \\
\hline 3 & 10.11 & 2.98 & 86.69 & 0.03 & 0.20 \\
\hline 4 & 10.11 & 2.98 & 86.69 & 0.03 & 0.20 \\
\hline 5 & 10.11 & 2.98 & 86.69 & 0.03 & 0.20 \\
\hline \multicolumn{6}{|c|}{ Variance Decomposition of RETSCI: } \\
\hline Period & RETBVSP & RETMICEX & RETSENSEX & RETSCI & RETSAF40 \\
\hline 1 & 1.26 & 0.05 & 0.75 & 97.94 & 0.00 \\
\hline 2 & 1.55 & 0.06 & 0.78 & 97.60 & 0.02 \\
\hline 3 & 1.55 & 0.06 & 0.78 & 97.60 & 0.02 \\
\hline 4 & 1.55 & 0.06 & 0.78 & 97.60 & 0.02 \\
\hline 5 & 1.55 & 0.06 & 0.78 & 97.60 & 0.02 \\
\hline \multicolumn{6}{|c|}{ Variance Decomposition of RETSAF40: } \\
\hline Period & RETBVSP & RETMICEX & RETSENSEX & RETSCI & RETSAF40 \\
\hline 1 & 0.00 & 0.00 & 0.00 & 0.03 & 99.96 \\
\hline 2 & 0.00 & 0.00 & 0.01 & 0.11 & 99.88 \\
\hline 3 & 0.00 & 0.00 & 0.01 & 0.11 & 99.88 \\
\hline 4 & 0.00 & 0.00 & 0.01 & 0.11 & 99.88 \\
\hline 5 & 0.00 & 0.00 & 0.01 & 0.11 & 99.88 \\
\hline
\end{tabular}

\section{Conclusions}

The existing evidence clearly shows that global financial volatilities are moving together and the correlations are increasing with higher instability and deeper crisis. A model which could lend a helping hand in determining the intricacies and capture the structure of financial market is need of the hour. Such models find scope in asset pricing, portfolio selection, option pricing, hedging and risk management.

The study investigated the correlation and co-movement among BRICS markets. High correlations would indicate that the equities of these countries offer few or no portfolio diversification opportunities. Granger causality, Johansen cointegration test and VAR are applied to test contemporaneous connections among these markets. The findings of Granger causality test indicate BVSP has causality running to all other markets except SAF40. This finding is indeed useful as the Brazilian market has not been perceived as a lead indicator for variations or fluctuations in other markets in the world. Johansen cointegration test has revealed no long-run co-movement among these markets. The VAR results show that Brazilian market impacts fluctuations in all other BRICS market except South Africa, but not to a very large extent. The effect of other markets on each other is negligible. This implies that the Brazilian, Russian, Indian, Chinese and South African equities offer good portfolio diversification opportunities to investors seeking to invest in internationally diversified portfolios. The correlations, as given in table 11, between the pairs of these markets are also quite low, in fact, negative in certain cases. This confirms lucrative diversification opportunity as postulated by modern portfolio theory (Markowitz, 1952).

Table 11. Correlation matrix

\begin{tabular}{llllll}
\hline & RETSCI & RETSENSEX & RETMICEX & RETSAF40 & RETBVSP \\
\hline RETSCI & 1.00 & 0.22 & 0.20 & 0.03 & 0.17 \\
RETSENSEX & 0.22 & 1.00 & 0.40 & -0.03 & 0.28 \\
RETMICEX & 0.20 & 0.40 & 1.00 & -0.01 & 0.39 \\
RETSAF40 & 0.03 & -0.03 & -0.01 & 1.00 & -0.01 \\
RETBVSP & 0.17 & 0.28 & 0.39 & -0.01 & 1.00 \\
\hline
\end{tabular}

The robustness of these findings have been evaluated by estimating VAR again, using the time zone ordering, that is, testing the transmission of shock in the context of the opening time of the exchange. Thus, the VAR ordering followed is China, India, Russia, South Africa and Brazil. The results are given in table 12.

Table 12. Variance decomposition estimation (2010-2017) with time zone ordering

\begin{tabular}{llllll}
\hline $\begin{array}{l}\text { Variance } \\
\text { Decomposition } \\
\text { of RETSCI }\end{array}$ & & & & & \\
\hline Period & RETSCI & RETSENSEX & RETMICEX & RETSAF40 & RETBVSP \\
1 & 100.00 & 0.00 & 0.00 & 0.00 & 0.00 \\
2 & 98.25 & 0.46 & 0.22 & 0.09 & 0.99 \\
3 & 98.24 & 0.46 & 0.22 & 0.09 & 0.99 \\
4 & 98.24 & 0.46 & 0.22 & 0.09 & 0.99 \\
5 & 98.24 & 0.46 & 0.22 & 0.09 & 0.99 \\
Variance & & & & & \\
\hline
\end{tabular}




\begin{tabular}{|c|c|c|c|c|c|}
\hline \multicolumn{6}{|l|}{$\begin{array}{l}\text { Decomposition } \\
\text { of RETSENSEX: }\end{array}$} \\
\hline Period & RETSCI & RETSENSEX & RETMICEX & RETSAF40 & RETBVSP \\
\hline 1 & 4.24 & 95.76 & 0.00 & 0.00 & 0.00 \\
\hline 2 & 4.13 & 91.54 & 0.43 & 0.09 & 3.81 \\
\hline 3 & 4.13 & 91.52 & 0.43 & 0.10 & 3.82 \\
\hline 4 & 4.13 & 91.52 & 0.43 & 0.10 & 3.82 \\
\hline 5 & 4.13 & 91.52 & 0.43 & 0.10 & 3.82 \\
\hline \multicolumn{6}{|l|}{ Variance } \\
\hline \multicolumn{6}{|l|}{ Decomposition } \\
\hline Period & RETSCI & RETSENSEX & RETMICEX & RETSAF40 & RETBVSP \\
\hline 1 & 3.65 & 12.25 & 84.09 & 0.00 & 0.00 \\
\hline 2 & 3.61 & 12.06 & 82.65 & 0.00 & 1.68 \\
\hline 3 & 3.61 & 12.06 & 82.64 & 0.00 & 1.69 \\
\hline 4 & 3.61 & 12.06 & 82.64 & 0.00 & 1.69 \\
\hline 5 & 3.61 & 12.06 & 82.64 & 0.00 & 1.69 \\
\hline \multicolumn{6}{|l|}{ Variance } \\
\hline \multicolumn{6}{|l|}{ Decomposition } \\
\hline Period & RETSCI & RETSENSEX & RETMICEX & RETSAF40 & RETBVSP \\
\hline 1 & 0.06 & 0.23 & 0.00 & 99.71 & 0.00 \\
\hline 2 & 0.06 & 0.23 & 0.01 & 99.51 & 0.19 \\
\hline 3 & 0.06 & 0.23 & 0.01 & 99.50 & 0.19 \\
\hline 4 & 0.06 & 0.23 & 0.01 & 99.50 & 0.19 \\
\hline 5 & 0.06 & 0.23 & 0.01 & 99.50 & 0.19 \\
\hline \multicolumn{6}{|l|}{ Variance } \\
\hline \multicolumn{6}{|l|}{ Decomposition } \\
\hline Period & RETSCI & RETSENSEX & RETMICEX & RETSAF40 & RETBVSP \\
\hline 1 & 3.11 & 6.54 & 8.91 & 0.00 & 81.43 \\
\hline 2 & 3.12 & 6.56 & 8.89 & 0.16 & 81.27 \\
\hline 3 & 3.12 & 6.56 & 8.89 & 0.16 & 81.27 \\
\hline 4 & 3.12 & 6.56 & 8.89 & 0.16 & 81.27 \\
\hline 5 & 3.12 & 6.56 & 8.89 & 0.16 & 81.27 \\
\hline
\end{tabular}

The results of re-estimated VAR also confirm the findings of the previous VAR estimations given in table 9. 98 per cent of China's variations come from its own innovation from day 2 to day 5 with Brazil contributing 1 per cent of the remaining impact. 91 per cent of India's fluctuation comes from its own movements and the balance majorly comes from China and Brazil, each contributing 4 per cent. 12 per cent of Russia's variation is attributable to India, 4 per cent China and 2 per cent to Brazil. South Africa is impacted almost 100 per cent by its own shock on all the days, impact of movements in other BRICS markets is negligible. 81 per cent of Brazil's variance comes from its own movements and the balance is 9 per cent from Russia, 6 per cent from India and 3 per cent from China.

VAR estimates generated and reported in table 10 also indicate more or less the same relationship among these markets. This shows that the global financial crisis has not altered the dynamics among the equity markets of these countries significantly. This information is invaluable to portfolio investors who may be looking for a long holding period.

\section{References}

1. Akaike, H. A (1974), New Look at the Statistical Model Identification, I.E.E.E. Transactions on Automatic Control, Volume 19, Issue 6, pp. 716-723.

2. Cerny, A. (2004), Stock Market Integration and the Speed of Information Transmission, SSRN Electronic Journal. 10.2139/ssrn.849004., Available At: http://dx.doi.org/10.2139/ssrn.849004.

3. Chandran, V.G.R. and Rao, R. (2009), Stock Interdependencies: The Case of an Emerging East Asian Economy. The IUP Journal of Applied Economics, Volume 8, Issue 5-6, pp. 73-82.

4. Dickey, D.A. and Fuller, W.A. (1979), Distribution of the Estimators For Autoregressive Time Series With A Unit Root. Journal of the American Statistical Association, Volume 74, Issue 366, pp. 427-431.

5. Dickey, D.A. and Fuller, W.A.(1981), Likelihood Ratio Statistics for Autoregressive Time Series with a Unit Root, Econometrica, Volume 49, Issue 4, pp. 1057-1072.

6. Folfas, P. (2016), Co-Movements of NAFTA Stock Markets: Granger-Causality Analysis. Economics and Business Review, Volume 2 (16), Issue 1, pp. 53-65.

7. Granger, C.W.J. (1969), Investigating Causal Relations by Econometric Models and Cross-Spectral Methods. Econometrica, Volume 37, Issue 3, pp. 424-438.

8. Granger, C.W.J. (1988), Some Recent Developments in a Concept of Causality. Journal of Econometrics, Volume 39, Issue 1-2, pp. 199211.

9. Granger, C.W.J and Newbold, P. (1974), Spurious Regressions in Econometrics. Journal of Econometrics, Volume 2, Issue 2, pp. 111-120.

10. Hannan, E.J. and Quinn, B.G. (1979), The Determination of the Order of an Autoregression. Journal of the Royal Statistical Society, Volume 41, Issue 2, pp. 190-195.

11. Johansen, S. (1991), Estimation and Hypothesis Testing of Cointegration Vectors in Gaussian Vector Autoregressive Models, Econometrica, Volume 59, Issue 6, pp. 1551-1580.

12. Markowitz, H. (1952), Portfolio Selection, Journal of Finance, Volume 7, Issue 1, pp. 77-91. 
13. Plíhal,T. (2016), Granger Causality between Stock Market and Macroeconomic Indicators: Evidence from Germany. Acta Universitatis Agriculturae et Silviculturae Mendelianae Brunensis, Volume 64, Issue 6, pp. 2101-2108.

14. Schwarz, G. (1978), Estimating the Dimension of a Model. The Annals of Statistics, Volume 6, Issue 2 pp. 461-464.

15. Sims, C. (1980), Macroeconomics and Reality. Econometrica, Volume 48, Issue 1, pp. 1-48.

16. Vyrost, T. and Baumöhl, E. (2000), Stock Market Integration: Granger Causality Testing with Respect to Nonsynchronous Trading Effects. Czech Journal Of Economics And Finance, Volume 60, Issue 5, pp. 414-425.

17. Zeren, F. and Koç, M. (2016), Time Varying Causality between Stock Market and Exchange Rate: Evidence from Turkey, Japan and England. Economic Research-Ekonomska Istraživanja, Volume 29, Issue 1, pp. 696-705. 